\title{
Hipnosis Lima Jari dengan Pendekatan Spiritual Menurunkan Insomnia pada Lansia
}

\author{
Dudi Hartono ${ }^{1}$, Iwan Somantri ${ }^{2}$, Sofia Februanti ${ }^{3}$ \\ Jurusan Keperawatan, Politeknik Kesehatan Tasikmalaya, Indonesia \\ Email:duhar09@gmail.com
}

\begin{abstract}
Five-Finger Hypnosis with Spiritual Approach Reduces Insomnia in the Elderly. Sleep needs are basic human needs, including the elderly. However, many elderly people have difficulty sleeping (insomnia). This study aimed to determine the effect of a five-finger spiritual hypnosis approach to insomnia experienced by the elderly. The study design used a quasiexperiment, with one group pretest-posttest design approach without a control group. Sampling using purposive sampling technique, with a total of 34 people. Elderly is assigned to do a 5-finger hypnosis technique with a spiritual approach independently every night before going to bed for up to three nights. Data analysis using univariate and bivariate. The results showed that after the elderly were intervened in the form of five-finger hypnosis with a spiritual approach for 3 days, there was an influence on the incidence of insomnia in the elderly p-value $=0,000(\mathrm{p}<0.05)$. Fivefinger hypnosis with a spiritual approach can reduce the incidence of insomnia in the elderly.
\end{abstract}

Keywords: Elderly insomnia, Five-finger hypnosis, Spiritual approach

\begin{abstract}
Abstrak: Hipnosis Lima Jari dengan Pendekatan Spiritual Menurunkan Insomnia pada Lansia. Kebutuhan tidur merupakan kebutuhan dasar manusia termasuk lanjut usia (lansia). Namun banyak lansia yang mengalami kesulitan tidur (insomnia). Tujuan penelitian ini adalah untuk mengetahui pengaruh hipnosis lima jari pendekatan spiritual terhadap insomnia yang dialami lansia. Desain penelitian menggunakan quasi experiment, dengan pendekatan one grouppre test- post test design tanpa kelompok kontrol. Pengambilan sampel dengan teknik purposivesampling, dengan jumlah 34 orang. Lansia ditugaskan untuk melakukan teknik hipnosis 5 jari dengan pendekatan spiritual secara mandiri pada setiap malam menjelang tidur sampai tiga malam. Analisis data menggunakan univariat dan bivariat. Hasil penelitian menunjukkan bahwa setelah lansia dilakukan intervensi berupa hipnosis lima jari dengan pendekatan spiritual selama 3 hari, terdapat pengaruh terhadap kejadian insomnia pada lansia $p$-value $=0,000(p<0,05)$. Hipnosis lima jari dengan pendekatan spiritual dapat menurunkan kejadian insomnia pada lansia.
\end{abstract}

Kata kunci: Insomnia lansia, Hipnosis lima jari, Pendekatan spiritual

\section{PENDAHULUAN}

Peningkatan usia harapan hidup menyebabkan jumlah lansia terus meningkat setiap tahun.Dalam waktu hampir lima dekade, persentase lansia Indonesia meningkat sekitar dua kali lipat (1971-2017), yakni menjadi 8,97\% (23,4 juta) dimana lansia perempuan sekitar satu persen lebih banyak dibandingkan lansia laki-laki $(9,47 \%$ banding $8,48 \%)$. Meningkatnya penduduk lansia membawa konsekuensi tersendiri terhadap pembangunan nasional, seperti menciptakan tantangan tersendiri yang menyentuh berbagai aspek kehidupan, baik kesehatan, sosial, ekonomi, maupun lingkungan(Maylasari, Sulistyowati, Ramadani, $\&$ Annisa, 2017). Salah satu masalah yang sering terjadi pada lansia adalah insomnia. Insomnia merupakan salah satu gangguan tidur ditandai dengan sulitnya memulai atau mempertahankan tidur yang menimbulkan gejala sulit berkonsentrasi dan gangguan suasana hati di siang hari (Patel, Steinberg, \& Patel, 2018).

Gangguan tidur diperkirakan terjadi 40$70 \%$ pada lansia (Praharaj, Gupta, \& Gaur, 2018). Insomnia yang terjadi secara global mempengaruhi sekitar 150 juta orang di negara berkembang. Prevalensi insomnia di Indonesia dilaporkan $10 \%$ dari jumlah populasi atau sekitar 28 juta orang (Mawaddha, 2017). Insomnia merupakan sumber tantangan yang signifikan terhadap perawatan pasien rawat inap lansia (Andrade, 2018). Hal ini disebabkan jika lansia mengalami insomnia maka akan mempengaruhi kesehatan fisik dan jiwa secara keseluruhan pada lansia tersebut. 
Penyebab insomnia pada lansia antara lain depresi, takut mati, tekanan dalam hidup, gangguan muskuloskeletal, gangguan pernafasan, khawatir pada anak-anak, kamar tidur yang dingin (El-Gilany, Saleh, El-Aziz, \& Elsayed, 2017). Insomnia kronis mempengaruhi $57 \%$ lanjut usia (lansia) di Amerika Serikat dengan gangguan kualitas hidup, gangguan fungsi, dan gangguan kesehatan (Abad \& Guilleminault, 2018). Insomnia kronis dapat membebani masyarakat baik dalam biaya perawatan langsung maupun tidak langsung dari akibat yang ditimbulkan oleh insomnia.Dampak insomnia pada lansia; misalnya mengantuk berlebihan di siang hari, gangguan atensi dan memori, mood depresi, sering terjatuh, penggunaan hipnotik yang tidak semestinya, dan penurunan kualitas hidup, kondisi kesehatan fisik yang buruk (Sumirta \& Laraswati, 2015; Wang et al., 2017)

Saat ini semakin banyak penelitian tentang cara penanganan insomnia. Penanganan insomnia dapat dilakukan dengan cara terapi psikologis/ perilaku, pengobatan farmakologis atau kombinasi keduanya. Pemberian terapi farmakologis dan non farmakologis (perilaku/ psikologis) ataupun kombinasi keduanya, diberikan pada lansia dengan memperhatikan efek samping pemberian terapi tersebut. Salah satu terapi psikologis/ perilaku untuk mengatasi insomnia adalah dengan terapi hipnosis (Lam \& Macina, 2017).

Terapi hipnosis merupakan salah satu terapi relaksasi. Terapi relaksasi adalah teknik yang menciptakan kondisi santai untuk sistem saraf otonom, untuk tetap menyuplai darah di otot, dan mengurangi konsumsi oksigen, detak jantung, keringat, dan aktivitas otot. Terapi hipnosis lima jari merupakan proses yang memanfaatkan kekuatan pikiran dengan menggerakkan tubuh untuk pemulihan diri dan menjaga kesehatan atau keadaan pikiran yang rileks melalui batin komunikasi yang melibatkan semua indera seperti penciuman, penglihatan, pendengaran (Davis \& McKay, 2008 dalam Dewi, Rahayuwati, \& Kurniawan, 2018). Pasien yang dilakukan hipnosis lima jari dapat menurunkan ketegangan otot, membantu memusatkan perhatian, mengurangi ketakutan, sehingga pasien merasa lebih rileks (Rizkiya, $\mathrm{PH}$, \& Susanti, 2017).

Terapi lainnya untuk mengatasi masalah insomnia adalah terapi dengan pendekatan spiritual. Prinsip yang mendasari pendekatan spiritual adalah keyakinan yang dianut dengan cara berdzikir mengingat dan menyebut namanama Allah serta menenangkan pikiran, meregangkan dan mengendorkan otot sekaligus mengatur pernapasan sehingga mendapatkan respon relaksasi(Khoirudin, 2018). Hal ini akan mempercepat keadaan rileks, sehingga menurunkan kejadian insomnia.

Penelitian ini bertujuan untuk mengetahui pengaruh hipnosis lima jari pendekatan spiritual terhadap insomnia yang dialami lansia di Rumah Perlindungan Sosial Tresna Wredha Garut pada tahun 2017

\section{METODE}

Desain penelitian yang digunakan adalah Quasy Eksperiment dengan pendekatan One Group Pretest-Posttest Design tanpa kelompok kontrol. Penelitian dilakukan di Rumah Perlindungan Sosial Tresna Werda (RPSTW) Garut, selama bulan September sampai Oktober 2017. Pemilihan sampel menggunakan teknik purposive sampling dengan jumlah 34 orang lansia, dengan kriteria berusia minimal 60 tahun, dapat mendengar dan melihat, tidak mengalami demensia, dan tidak minum obat tidur selama seminggu terakhir, tidak mengalami gangguan jiwa. Teknik pengumpulan data dilakukan dengan cara mengurus izin penelitian kemudian mencari calon responden yang sesuai kriteria dan dijelaskan informed consent. Setelah responden menandatangani informed consent, responden diberikan pre test berupa kuesioner (pengambilan data awal insomnia). Lansia dilatih oleh peneliti untuk melakukan teknik hipnosis 5 jari dengan pendekatan spiritual sampai melakukan mandiri sesuai dengan Standar Operasional Prosedur (SOP) yang telah dibuat. Lansia ditugaskan untuk melakukan teknik hipnosis 5 jari dengan pendekatan spiritual secara mandiri pada setiap malam menjelang tidur sampai tiga malam. Supervisi dilakukan oleh peneliti atau perawat RPSTW Garut. Pada hari keempat, tim peneliti melakukan pengambilan data insomnia (post test). Analisis data dengan univaiat dan bivariat.

Penelitian ini telah mendapat persetujuan etik penelitian dari Komisi Etik Penelitian Kesehatan Politeknik Kesehatan Kemenkes Bandung Nomor: 09/KEPK/PE/IX/2017. 
HASIL

Tabel 1. Karakteristik Responden Berdasarkan Jenis Kelamin, Pendidikan, Status Marital, Penyakit Fisik, Masalah Lingkungan, Masalah Pikiran

\begin{tabular}{lrr}
\hline \multicolumn{1}{c}{ Karakteristik responden } & f & \% \\
\hline Jenis kelamin: & & \\
Laki- laki & 15 & 44 \\
Perempuan & 19 & 56 \\
\hline Pendidikan: & & \\
Tidak tamat SD & 7 & 20 \\
SD & 19 & 56 \\
SMP & 3 & 9 \\
SMU & 4 & 12 \\
PT & 1 & 3 \\
\hline Status marital: & & \\
Menikah & 7 & 20,6 \\
Duda/Janda & 27 & 79,4 \\
\hline Penyakit fisik: & & \\
Ya & 21 & 62 \\
Tidak & 13 & 38 \\
\hline Masalah lingkungan: & & \\
Ya & 7 & 20,6 \\
Tidak & 27 & 79,4 \\
\hline Masalah pikiran: & & \\
Ya & 9 & 16,1 \\
Tidak & 25 & 83,9 \\
\hline
\end{tabular}

Berdasarkan tabel 1diperoleh jenis kelamin lansia terbanyak adalah perempuan, dengan pendidikan terbanyak SD (56\%), status marital janda/duda $(79,4 \%)$, memiliki penyakit fisik (62\%), tidak memiliki masalah lingkungan $(79,4 \%)$, tidak memiliki masalah pikiran $(83,9 \%)$.

Tabel 2. KarakteristikResponden Berdasarkan Umur Lansia

\begin{tabular}{rrrr}
\hline Min & Max & Mean & Standar deviasi \\
\hline 60 & 87 & 70,75 & 7,638 \\
\hline
\end{tabular}

Berdasarkan tabel 2 didapatkan hasil bahwa usia terendah adalah 60 tahun, usia tertinggi 87 tahun, dengan rata-rata usia 70,75 tahun, dengan standar deviasi 7,638.

Tabel 3. Distribusi Kejadian Insomnia pada Lansia sebelum Diintervensi

\begin{tabular}{lrc}
\hline \multicolumn{1}{c}{$\begin{array}{c}\text { Kejadian Insomnia } \\
\text { sebelum Diintervensi }\end{array}$} & \multicolumn{1}{c}{ f } & \% \\
\hline Ringan & 31 & 91,2 \\
Berat & 3 & 18,8 \\
\hline
\end{tabular}

Berdasarkan tabel 3 diperoleh bahwa kejadian insomnia pada lansia sebelum diintervensi hipnosis lima jari dengan pendekatan spiritual berada pada kategori ringan $(91,2 \%)$.
Tabel 4. Distribusi Kejadian Insomnia setelah Diintervensi

\begin{tabular}{lrr}
\hline $\begin{array}{c}\text { Kejadian insomnia } \\
\text { setelah diintervensi }\end{array}$ & \multicolumn{1}{c}{ f } & \multicolumn{1}{c}{$\%$} \\
\hline Tidak ada keluhan & 29 & 85,3 \\
Ringan & 5 & 14,7 \\
Berat & 0 & 0 \\
\hline
\end{tabular}

Berdasarkan tabel 4 diperoleh hasil bahwa kejadian insomnia pada lansia setelah diintervensi hipnosis lima jari dengan pendekatan spiritual berada pada kategori tidak ada keluhan yaitu sebesar $85,3 \%$.

Tabel 5. Hasil Penghitungan Uji T Pengaruh Hipnosis Lima Jari Pendekatan Spiritual terhadap Insomnia pada Lansia setelah 3 Hari Intervensi

\begin{tabular}{lccc}
\hline \multicolumn{1}{c}{ Mean } & $\begin{array}{c}\text { Mean } \\
\text { diff }\end{array}$ & t & $\begin{array}{c}\boldsymbol{p} \text { - } \\
\text { value }\end{array}$ \\
\hline $\begin{array}{l}\text { Pre test } 22,5 \\
\text { Post test } 17,47\end{array}$ & 3,261 & 8,995 & 0,000 \\
\hline
\end{tabular}

Berdasarkan tabel 5 didapatkan bahwa hasil uji paired $t$ test, diperoleh $\rho$-value 0,00 menunjukkan bahwa nilai $\rho$-value kurang dari $\alpha$ $(\mathrm{p}<0,05)$.Penelitian ini dapat disimpulkan bahwa terdapat pengaruh hipnosis lima jari dengan pendekatan spiritual terhadap kejadian insomnia lansia di RPSTW Garut.

\section{PEMBAHASAN}

Perubahan spesifik pada lansia dipengaruhi kondisi kesehatan, gaya hidup, stressor, dan lingkungan. Selain itu, beberapa faktor demografis, psikososial, biologis, dan perilaku dapat berkontribusi terhadap kejadian insomnia di pada lansia (Patel et al., 2018). Perawatan pada lansia, idealnya dimulai dengan terapi nonfarmakologis, seperti mengatasi masalah kebersihan, tidur, dan olahraga (Raman \& Roy, 2019). Berbagai bidang yang menjadi perhatian termasuk penggunaan rutin obat-obatan bebas yang mengandung antihistamin, yang harus dihilangkan, dan konsumsi alkohol yang berpotensi untuk disalahgunakan dan tidak boleh digunakan sebagai bantuan tidur. Perawat harus mengetahui proses perubahan normal tersebut sehingga dapat memberikan pelayanan tepat dan membantu adaptasi lansia terhadap perubahan, salah satunya adalah perubahan neurologis. Akibat penurunan jumlah neuron fungsi neurotransmitter juga berkurang. Lansia sering mengeluh kesulitan untuk tidur, kesulitan untuk tetap terjaga, kesulitan untuk tidur kembali tidur setelah terbangun di malam hari, terjaga terlalu 
cepat, dan tidur siang yang berlebihan. Masalah ini diakibatkan oleh perubahan terkait usia dalam siklus tidur-terjaga (Potter \& Perry 2009 dalam Sumirta \& Laraswati, 2015).

Hasil penelitian menunjukkan bahwa $p$ value 0,00 artinya terapi hipnosis lima jari dengan pendekatan spiritual dapat menurunkan kejadian insomnia lansia.Pilihan pengobatan nonfarmakologis memiliki manfaat yang menguntungkan dan bertahan lama dibandingkan dengan terapi farmakologis (Patel et al., 2018). Artinya terapi non farmakologis berupa terapi hipnosis lima jari memiliki manfaat dan bertahan lama dalam menurunkan kejadian insomnia. Terapi hipnosis lima jari ini tidak memiliki efek samping. Hal ini sejalan dengan hasil penelitian Dewi et al (2018) bahwa terapi hipnosis lima jari dapat mempengaruhi kualitas tidur pasien kanker payudara.

Hipnosis lima jari dapat mempengaruhi pernapasan, denyut jantung, denyut nadi, tekanan darah, mengurangi ketegangan otot dan koordinasi tubuh, dan memperkuat ingatan, meningkatkan produktivitas suhu tubuh, serta mengatur hormon-hormon yang berkaitan dengan stres. Sebagian besar perubahan fisiologis terjadi akibat aktivitas dua sistem neuroendokrin yang dikendalikan oleh hipotalamus yaitu sistem simpatis dan sistem korteks adrenal. Menurut Mahoney, (2007, dalam Hastuti \& Arumsari, 2015) menyatakan bahwa hipnosis lima jari merupakan self hypnosis yang mampu memberikan efek relaksasi yang tinggi, sehingga mengurangi atau menurunkan tingkat ketegangan dan stress yang ada dalam pikiran seseorang (Affandi, 2017). Sedangkan menurut Simatupang \& Putri (2015), relaksasi hipnosis lima jari menurunkan cemas dengan cara menciptakan suatu sugesti kepada individu yang akan dihipnosis

Hipnosis lima jari sangat efektif untuk menurunkan kejadian insomnia jika dilakukan secara rutin dan teratur. Teknik ini menciptakan tanggapan emosional dan efek yang menenangkan. Terapi hipnosis ini bertujuan membantu menyelesaikan masalah pikiran/emosi yang dirasakan oleh penderita insomnia atau susah tidurdengan cara mengatasi penyebab masalah yaitu penyebab aktifnya pikiran saat waktunya istirahat tidur. Seseorang dapat belajar kembali merasakan peristiwa dalam kehidupannya yang menyenangkan melalui bayangan yang dihadirkan kembali. Ketika seseorang dalam keadaan terhipnosis akan merasakan tingkat relaksasi yang tinggi, pikiran dan perasaan pasien terfokus pada suatu kondisi yang terpisah dari lingkungan. Ketegangan otot dan ketidaknyaman akan dikeluarkan sehingga tubuh menjadi rileks dan nyaman. Perasaan yang dirasakan penderita saat ini misalnya kecemasan, takut,gelisah atau apapun emosi tersebut belum tentu merupakan akar permasalahan sebenarnya (Rizkiya et al., 2017).

Terapi nonfarmakologis lain untuk menangani insomnia pada lansia adalah dengan pendekatan spiritual. Spritual berhubungan dengan atau bersifat kejiwaan (rohani batin). Lansia yang memilikipengalaman spiritual yang lebih banyak setiap hari, umumnya jarang memiliki masalah kesehatan. Artinya lansia menjadi jarang mengalami gangguan kesehatan secara fisik seperti insomnia (Sharifi, Moeini, Bromand, \& Binayi, 2019). Hal ini sejalan dengan hasil penelitian Silveira, Giacomin, Dias, \& Firmo (2018) bahwa pengalaman religius memberikan manfaat bagi lansia untuk penyembuhan terhadap keluhan yang dialami lansia. Beberapa hasil penelitian dengan pendekatan spiritual pada lansia yang mengalami insomnia, maka didapatkan hasil bahwa adanya peningkatan kualitas tidur pada lansia (Arnata, Rosalina, \& Lestari, 2018). Penanganan masalah kesehatan mental pada lansia dengan menekankan dimensi spiritual memberikan kontribusi terhadap peningkatan kesehatan lansia (Heidari, Borujeni, Abyaneh, \& Rezaei, 2019).

Pada penelitian ini, peneliti menggabungkan hipnosis lima jari dengan Do'a sebelum tidur. Doa sebelum tidur merupakan salah satu aspek spiritual. Bagi orang Islam, ada beberapa amalan yang dianjurkan, sebagaimana dicontohkan Nabi Muhammad SAW, yaitu membaca surat Al Ikhlas, membaca sholawat kepada nabi, beristighfar bagi kaum muslimin dan muslimat, bertasbih dan juga hendaknya membaca do'a tidur. Bila kedua aspek ini dapat dilakukan oleh lansia yang mengalami insomnia, maka masalah gangguan tidur akan teratasi karena tercapai kedamaian hati akan dan bernilai ibadah. Peneliti menggabungkan terapi hipnosis dan pendekatan spiritual secara Islam dalam menangani insomnia pada lansia karena seluruh responden dalam penelitian ini beragam Islam.

Pada penelitian ini, terapi hipnosis lima jari dengan pendekatan spiritual efektif menurunkan insomnia pada lansia.

\section{SIMPULAN}

Kejadian insomnia pada lansia sebelum diintervensi hipnosis lima jari dengan pendekatan spiritual berada pada kategori ringan dan berat. 
Kejadian insomnia pada lansia setelah diintervensi hipnosis lima jari dengan pendekatan spiritual berada pada kategori tidak ada keluhan dan ringan. Ada pengaruh hipnosis lima jari dengan pendekatan spiritual terhadap insomnia yang dialami lansia ( $p$-value 0,000$)$.

\section{DAFTAR PUSTAKA}

Abad, V. C., \& Guilleminault, C. (2018). Insomnia in Elderly Patients: Recommendations for Pharmacological Management. Drugs and Aging, 35(9), 791-817.

https://link.springer.com/article/10.1007/s4 0266-018-0569-8

Affandi, I. M. (2017). Pengaruh Terapi Relaksasi Napas Dalam Dan Hypnosis Lima Jari Terhadap Tingkat Stress Mahasiswa Program Studi Ilmu Keperawatan Universitas 'Aisyiyah Yogyakarta. (Naskah Publikasi, Fakultas Ilmu Kesehatan, Universitas 'Aisyiyah Yogyakarta). http://digilib.unisayogya.ac.id/2540/1/Nask ah Publikasi.pdf (30 Desember 2017).

Andrade, C. (2018). Sedative Hypnotics and the Risk of Falls and Fractures in the Elderly. The Journal of Clinical Psychiatry, 79(3).

Arnata, A. P., Rosalina, \& Lestari, P. (2018). Pengaruh Terapi Spiritual Emotional Freedom Technique (SEFT) Terhadap Peningkatan Kualitas Tidur pada Lansia di Desa Gondoriyo Kecamatan Bergas Kabupaten Semarang. Indonesia Journal of Nursing Research, 1(1), 48-61.

Dewi, R., Rahayuwati, L., \& Kurniawan, T. (2018). The Effect of Five-Finger Relaxation Technique to The Sleep Quality of Breast Cancer Patients. Padjadjaran Nursing Journal, 6(2), 183-192.

El-Gilany, A.-H., Saleh, N. M. H., El-Aziz, H. N. A., \& Elsayed, E. B. M. (2017). Prevalence of insomnia and its associated factors among rural elderly: a community based study. International Journal of Advanced Nursing Studies, 6(1), 56. https://doi.org/10.14419/ijans.v6i1.7415

Hastuti, R. Y., \& Arumsari, A. (2015). Pengaruh Terapi Hipnosis Lima Jari Untuk Menurunkan Kecemasan Pada Mahasiswa Yang Sedang Menyusun Skripsi Di Stikes Muhammadiyah Klaten. MOTORIK Jurnal Ilmu Kesehatan (Journal Of Health Science), 10(21), 25-35.

Heidari, M., Borujeni, M. G., Abyaneh, S. K., \& Rezaei, P. (2019). The Effect of Spiritual Care on Perceived Stress and Mental Health Among the Elderlies Living in Nursing Home. Journal of Religion and
Health, 58(4).

Khoirudin, M. A. (2018). Pengaruh Terapi Relaksasi Dzikir Terhadap Perubahan Tingkat Insomnia Pada Lansia di UPT Pelayanan Sosial Tresna Werdha Blitar di Tulungagung. (Skripsi, IAIN Tulungagung). $\quad$ http://repo.iaintulungagung.ac.id/9987/

Lam, S., \& Macina, L. O. (2017). Therapy Update for Insomnia in the Elderly. The Consultant Pharmacist, 32(10). https://www.ingentaconnect.com/contento ne/ascp/tcp/2017/00000032/00000010/art0 0006

Mawaddha, R. (2017). Penderita Insomnia di Indonesia Mencapai 28 Juta Orang. Lifestyle. https://lifestyle.bisnis.com/read/20171204/ 106/714937/penderita-insomnia-diindonesia-mencapai-28-juta-orang-

Maylasari, I., Sulistyowati, R., Ramadani, K. D., \& Annisa, L. (2017). Statistik Penduduk Lanjut usia 2017. Jakarta: Badan Pusat Statistik.

Patel, D., Steinberg, J., \& Patel, P. (2018). Insomnia in the Elderly: A Review. J Clin Sleep Med, 14(6), 1017-1024.

Praharaj, S. K., Gupta, R., \& Gaur, N. (2018). Clinical Practice Guideline on Management of Sleep Disorders in the Elderly. Indian J Psychiatry, 60(3).

Raman, S., \& Roy, A. (2019). Insomnia-A general review. Drug Invention Today, 12(1).

Rizkiya, K., PH, L., \& Susanti, Y. (2017). Pengaruh Tehnik 5 Jari Terhadap Tingkat Ansietas Klien Gangguan Fisik yang Dirawat di RSU Kendal. Jurnal Keperawatan Muhammadiyah, 1(2), 1-9. http://download.portalgaruda.org/article.ph $\mathrm{p}$ ? article $=530720 \& \mathrm{val}=10889 \&$ title $=$ Peng aruh Tehnik 5 Jari Terhadap Tingkat Ansietas Klien Gangguan Fisik Yang Dirawat Di RSU Kendal

Sharifi, S., Moeini, M., Bromand, S., \& Binayi, N. (2019). The Relationship between Daily Spiritual Experiences and General Health of the Elderly Registered in the Retirement Center of Isfahan Somayeh. Iranian Journal of Health Sciences 2019; , 7(1), 18- 
25

Silveira, D. R., Giacomin, K. C., Dias, R. C., \& Firmo, J. O. A. (2018). The fabric of resilience among the elderly and the reinvention of the self despite the difficulties faced. Rev. Bras. Geriatr. Gerontol., 21(3).

Simatupang, L., \& Putri, Y. S. E. (2015). Penanganan Ansietas dengan Cara Hipnosis Lima Jari dan Mendengarkan Musik pada Penderita Diabetes Mellitus
Tipe 2 dan Gagal Ginjal Kronik di RSMM. Jurnal Keperawatan Jiwa, 3(1), 66-72.

Sumirta, I. N., \& Laraswati, A. I. (2015). Faktor Yang Menyebabkan Gangguan Tidur (Insomnia) Pada Lansia. Keperawatan Politeknik Kesehatan Denpasar, 20, 1-10.

Wang, Y.-M., Song, M., Wang, R., Shi, L., He, J., Fan, T.-T., \& Wen-Hao. (2017). Insomnia and Multimorbidity in the Community Elderly in China. Journal of Clinical Sleep Medicine, 15(1). 